Konservasi Hayati, 17 (2): 69-74, Oktober (2021)

https://ejournal.unib.ac.id/index.php/hayati/

p-ISSN: 0216-9487

email:konservasihayati@unib.ac.id

e-ISSN: 2722-1113

\title{
KERAGAAN HASIL DAN KOMPONEN HASIL BEBERAPA VARIETAS KEDELAI PADA LINGKUNGAN GENANGAN
}

\author{
Rina Artari ${ }^{1 *}$, Pratanti Haksiwi Putri ${ }^{1}$, Heru Kuswantoro ${ }^{1}$ \\ ${ }^{1}$ Balai Penelitian Tanaman Aneka Kacang dan Umbi \\ *corresponding author : rinaartari@gmail.com
}

\begin{abstract}
The research aimed to evaluate the yield performance and yield components of several soybean varieties against the waterlogging environment. The research was conducted at the Balitkabi in February until May 2017. The experimental design used Randomized Block Design with two factors and four replications. The first factor is optimal environmental (L1) and waterlogging environment (L2). The second factor is soybean varieties. The varieties used in this study were 3 varieties of soybeans (Grobogan, Demas 1, and Dega 1). In the optimal environment (L1), the plants were planted in buckets that were planted under normal conditions . In the waterlogging treatment (L2), the polybags filled with soil and put into a wooden tub and added water. Waterlogging treatment is carried out after the plants are 21 days after planting, the wooden tub is filled with water to a height of $5 \mathrm{~cm}$ from the soil surface in the polybags (the plants are in submerged). The fertilizer used in this research was 15\% N, 15\% P2O5, 15\% K2O with a dose of $1.5 \mathrm{~g} /$ polybags or the equivalent of $250 \mathrm{~kg} \mathrm{ha}{ }^{-1}$ which was applied at planting. Observations were made on the character of the pods per plant, seeds per plant, seed weight, plant height, shoot fresh weight and shoot dry weight, root fresh weight and root dry weight and chlorophyll index. The waterloggingresulted in a decrease in yield components and soybean yield compared to the optimal environment. Waterlogging increased the root dry weight. Grobogan and Dega 1 varieties produced higher seed weights than Demas 1 varieties in waterlogging environments.
\end{abstract}

Keywords: Soybean, Waterlogging, Yield Component

\begin{abstract}
ABSTRAK
Tujuan dari penelitian adalah untuk mengetahui keragaan hasil dan komponen hasil dari beberapa varietas kedelai terhadap lingkungan genangan. Penelitian di lakukan di Rumah Kasa Balitkabi pada bulan Februari-Mei 2017. Rancangan percobaan yang digunakan adalah rancangan acak kelompok faktorial terdiri dari dua faktor dan empat kali ulangan. Faktor pertama yaitu perlakuan lingkungan tanpa genangan (L1) dan lingkungan genangan (L2). Faktor ke dua adalah varietas kedelai. Varietas yang digunakan dalam penelitian adalah 3 varietas kedelai (Grobogan, Demas 1, dan Dega 1). Pada perlakuan tanpa genangan (L1), tanaman di tanam dalam ember ditanam pada kondisi normal (tidak digenangi). Pada perlakuan genangan (L2), polibag yang telah diisi tanah dimasukkan ke dalam bak kayu yang telah dilapisi plastik dan ditambahkan air. Perlakuan genangan dilakukan setelah tanaman berumur $21 \mathrm{hst}$, bak kayu diisi air sampai ketinggian $5 \mathrm{~cm}$ dari permukaan tanah dalam polibag (tanaman dalam keadaan tergenang). Pupuk yang digunakan dalam penelitian adalah pupuk Phonska (N 15\%, P2O5 15\%, K2O 15\%) dengan dosis 1,5 g/polibag atau setara 250 $\mathrm{kg} / \mathrm{ha}$ yang diaplikasikan saat tanam. Pengamatan dilakukan terhadap karakter polong isi per tanaman, jumlah biji pertanaman, bobot biji per tanaman, tinggi tanaman, bobot segar dan bobot kering tajuk, bobot segar dan bobot kering akar serta indeks klorofil. Perlakuan genangan mengakibatkan penurunan komponen hasil dan hasil kedelai sebanyak $\pm 85 \%$ dibandingkan dengan lingkungan tanpa genangan dan perlakuan genangan meningkatkan bobot akar sebanyak $\pm 60 \%$ dibandingkan perlakuan tanpa genangan. Varietas Grobogan dan Dega 1 menghasilkan bobot biji pertanaman $\pm 95 \%$ yang lebih tinggi dibandingkan varietas Demas 1 pada lingkungan genangan.
\end{abstract}

Kata Kunci: Genangan, Kedelai, Komponen Hasil 


\section{PENDAHULUAN}

Kandungan gizi kedelai yang tinggi mempunyai peran penting untuk perbaikan gizi masyarakat merupakan salah satu alasan kedelai menjadi komoditas prioritas utama pemerintah Indonesia selain komoditas padi dan jagung. Budidaya kedelai yang tepat merupakan salah satu kunci meningkatkan produktivitas kedelai. Namun faktor lingkungan sering kali menjadi kendala dalam budidaya kedelai. Curah hujan yang tinggi, daerah pasang surut atau lahan dengan sistem drainase yang buruk mengakibatkan kondisi genangan. Kondisi genangan mempengaruhi fisiologi pertumbuhan, bobot kering brangkasan, proses fotosintesis dan pembentukan polong dan berakibat pada menurunnya hasil produksi (Ara et al., 2015). Pada cekaman genangan tanaman mengalami stres yang disebabkan beberapa hal diantaranya kadar oksigen rendah, intensitas cahaya rendah, kekurangan nutrisi, dan risiko infeksi penyakit yang tinggi, daun menjadi klorosis, defoliasi dan berujung pada kematian tanaman (Islam et al., 2014; Tamang dan Fukao, 2015). Hal ini berkaitan dengan kekurangan oksigen didaerah akar ketika jaringan tanaman dalam kondisi terendam sehingga tanaman kekurangan oksigen ( Mimi, 2015)

Menurut Fatimah et al. (2016) bahwa kondisi genangan dapat menurunkan kandungan nitrogen daun, kadar klorofil, berat basah dan berat kering brangkasan. Penurunan berat kering mencapai 60,41\%. Perlakuan genangan menyebabkan perbedaan dalam alokasi fotosintat, pada perlakuan genangan rasio akar lebih tinggi dibandingkan tajuk dan juga konsentrasi etilen meningkat 200\% dibandingkan kondisi normal. Menurut percobaan Ara et al. (2015) pertumbuhan akar ditemukan lebih banyak pada cekaman genangan pada R1 dibandingkan pada R4, genotipe dengan pertumbuhan akar yang tinggi menandakan lebih toleran terhadap cekaman genangan sementara. Genangan air dapat mengakibatkan penurunan hasil beragam antara $20-75 \%$ dipengaruhi oleh fase pertumbuhan saat tercekam genangan dan lamanya penggenangan ( Sumarno et al., 1988).

Suhartina et al. (2016) melaporkan hasil biji galur kedelai Tgm/Anj-T205-1-750 dan Sib/Grob-V64-5-137 mampu mencapai hasil masing-masing 2,63 dan 2,71 t/ha pada lahan jenuh air. Genotipe yang toleran terhadap cekaman genangan mempunyai bobot kering total yang lebih besar dikarenakan lebih efisien memproduksi daun, batang dan akar juga dibandingkan genotipe yang rentan genangan. Informasi tentang karakter agronomi varietas kedelai pada cekaman genangan akan melengkapi teknologi budidaya kedelai di lahan genangan. Tujuan dari penelitian ini adalah untuk mengetahui keragaan dan komponen hasil beberapa varietas kedelai terhadap lingkungan genangan. Dari hasil penelitian ini diharapkan dapat digunakan sebagai informasi pengembangan budidaya kedelai adaptif di lahan genangan.

\section{METODE}

Penelitian Rumah Kaca Balitkabi pada bulan Februari-Mei 2017. Rancangan percobaan yang digunakan adalah rancangan acak kelompok faktorial yang terdiri dari dua faktor dan diulang empat kali. Faktor pertama yaitu perlakuan lingkungan tanpa genangan (L1) dan lingkungan genangan (L2). Faktor ke dua adalah varietas. Varietas yang digunakan dalam penelitian adalah 3 varietas kedelai (Grobogan, Demas 1 dan Dega 1). Pada perlakuan tanpa genangan (L1), tanaman ditanam dalam ember yang berisi tanah seberat $8 \mathrm{~kg}$ dan ditanam pada kondisi normal (tidak digenangi). Pada perlakuan genangan (L2), tanaman ditanam pada polibag yang berisi tanah seberat $8 \mathrm{~kg}$, dua tanaman per polibag. Kemudian polibag tersebut di masukkan ke dalam bak kayu yang telah dilapisi plastik (tinggi bak kayu $\pm 30 \mathrm{~cm}$ ). Kemudian ke dalam bak kayu ditambahkan air setinggi $5 \mathrm{~cm}$ dari dasar bak kayu. Tanaman ditanam 3 hari setelahnya (kondisi tanah dalam polibag sudah jenuh air), masing-masing polibag diisi dengan 2 tanaman. Setelah tanaman berumur 2 (hari setelah tanam) hst. bak kayu diisi air sampai setinggi $\pm 20 \mathrm{~cm}$ dari dasar bak kayu atau 
ketinggian $5 \mathrm{~cm}$ dari permukaan tanah dalam polibag (tanaman dalam keadaan tergenang). Kondisi tersebut dibiarkan sampai panen. Untuk menjaga kestabilan tinggi air dalam bak, dilakukan pengecekan pada pagi dan sore hari. Pupuk yang digunakan dalam penelitian adalah setara dengan $50 \mathrm{~kg} / \mathrm{ha}$ Urea +100 $\mathrm{kg} / \mathrm{ha} \quad \mathrm{SP} 36+100 \mathrm{~kg} / \mathrm{ha} \mathrm{KCl}$, yang diaplikasikan saat tanam. Pengendalian hama dan penyakit dilakukan secara intensif. Pengamatan dilakukan terhadap karakter polong isi per tanaman, jumlah biji pertanaman, bobot biji per tanaman, tinggi tanaman, bobot segar dan bobot kering tajuk, bobot segar dan bobot kering akar serta indeks klorofil menggunakan Chlorophylmeter SPAD-502 pada umur 20, 30, 40, dan 50 hst.
Data yang diperoleh kemudian dianalisis ragam, apabila terdapat beda nyata antar perlakuan, diuji lanjut menggunakan analisis BNT 5\%. Analisis data menggunakan program MSTATC.

\section{HASIL DAN PEMBAHASAN}

Berdasarkan analisis ragam didapatkan bahwa terdapat interaksi antara varietas kedelai dan lingkungan tumbuh pada karakter polong isi, jumlah biji per tanaman, bobot segar tajuk, bobot kering tajuk, indeks klorofil 40 hst dan indeks klorofil 50 hst. (Tabel 1). Hal tersebut menunjukkan bahwa masingmasing varietas mempunyai respon yang berbeda terhadap perlakuan genangan.

Tabel 1. Nilai Kuadrat tengah karakter agronomi kedelai pada dua lingkungan

\begin{tabular}{|c|c|c|c|c|}
\hline \multirow[b]{2}{*}{ Karakter } & \multicolumn{4}{|c|}{ Kuadrat Tengah } \\
\hline & Ulangan & $\begin{array}{l}\text { Lingkungan } \\
\text { tumbuh }\end{array}$ & Genotipe & Interaksi \\
\hline Polong isi & 6,81 & $5676,45^{*}$ & $591,22 *$ & $819,40^{*}$ \\
\hline Jumlah biji per tanaman (g) & 21,78 & $20703,5^{*}$ & $951,250 *$ & $2198,02 *$ \\
\hline Bobot biji per tanaman $(\mathrm{g})$ & 0,84 & $136,80 *$ & $9,24 *$ & 1,47 \\
\hline Tinggi tanaman $(\mathrm{cm})$ & 10,08 & 4,08 & $226,76^{*}$ & 34,27 \\
\hline Bobot segar tajuk (g) & 1,23 & $319,01 *$ & $2292,23 *$ & $305,57^{*}$ \\
\hline Bobot segar akar (g) & 0,30 & $25,83 *$ & $8,43 *$ & 0,27 \\
\hline Bobot kering tajuk (g) & 1,49 & $58,59^{*}$ & $178,78^{*}$ & $98,62 *$ \\
\hline Bobot kering akar (g) & 0,165 & $26,67^{*}$ & $1,53 *$ & 0,03 \\
\hline Indeks klorofil 20 hst & 2,72 & 47,60 & 17,94 & 4,21 \\
\hline Indeks klorofil 30 hst & 2,71 & $377,62 *$ & $8,65^{*}$ & 3,63 \\
\hline Indeks klorofil 40 hst & 2,78 & $1261,50 *$ & $34,75^{*}$ & $24,61^{*}$ \\
\hline Indeks klorofil 50 hst & 2,85 & $1245,60 *$ & $28,42 *$ & $114,03 *$ \\
\hline
\end{tabular}

Keterangan: Tanda * dibelakang angka menandakan beda nyata pada $\alpha 5 \%$

Perlakuan tanpa genangan (L1) dan genangan (L2) terhadap 3 varietas kedelai (Grobogan, Demas 1 dan Dega 1) mempunyai jumlah polong isi per tanaman yang berbeda nyata (Tabel 2). Cekaman genangan menyebabkan jumlah polong yang terisi jauh lebih rendah dibandingkan dengan tanpa genangan. Dari 3 varietas yang diuji, varietas Demas 1 menunjukkan jumlah polong isi yang lebih banyak dibandingkan dengan varietas Grobogan dan Dega 1. Sedangkan varietas Grobogan dan Dega 1, jumlah polong isi per tanaman tidak berbeda nyata. Pada kondisi pertumbuhan optimal jumlah polong pertanaman varietas Demas 1 dan Dega 1 dapat mencapai masing-masing 64 dan 29 polong per tanaman (Balitkabi, 2016). Terdapat interaksi yang nyata antara lingkungan dengan varietas pada jumlah polong isi pertanaman. Pada beberapa penelitian bahwa kondisi cekaman genangan pada fase generatif menyebabkan kehilangan hasil lebih tinggi dibandingkan genangan yang terjadi pada fase vegetatif (Hapsari dan Adie; 2010 Ara et al., 2015). 
Tabel 2. Jumlah polong isi, jumlah biji pertanaman, bobot biji pertanaman dan tinggi tanaman varietas kedelai pada dua dua lingkungan

\begin{tabular}{|c|c|c|c|c|c|c|c|c|}
\hline \multirow[t]{2}{*}{ Varietas } & \multicolumn{2}{|c|}{$\begin{array}{l}\text { Jumlah polong } \\
\text { isi }\end{array}$} & \multicolumn{2}{|c|}{$\begin{array}{c}\text { Jumlah biji per } \\
\text { tanaman }\end{array}$} & \multicolumn{2}{|c|}{$\begin{array}{c}\text { Bobot biji per } \\
\text { tanaman }\end{array}$} & \multicolumn{2}{|c|}{ Tinggi tanaman } \\
\hline & L1 & L2 & L1 & L2 & L1 & L2 & L1 & L2 \\
\hline Grobogan & $27,05 b$ & $7,52 \mathrm{c}$ & $59,82 b$ & $19,10 d$ & $6,80 \mathrm{a}$ & $1,30 \mathrm{c}$ & $63,97 b$ & $69,12 b$ \\
\hline Demas 1 & $57,62 \mathrm{a}$ & $3,50 \mathrm{c}$ & $98,32 \mathrm{a}$ & $1,32 \mathrm{f}$ & $3,87 b$ & $0,05 \mathrm{~d}$ & $76,70 \mathrm{a}$ & $73,60 \mathrm{a}$ \\
\hline Dega 1 & $23,77 b$ & $5,15 c$ & $47,27 \mathrm{c}$ & $8,77 \mathrm{e}$ & $5,95 \mathrm{a}$ & $0,95 \mathrm{c}$ & $65,20 \mathrm{~b}$ & $65,62 b$ \\
\hline Rata-rata & 36,15 & 5,39 & 68,47 & 9,73 & 5,54 & 0,76 & 68,62 & 69,45 \\
\hline$\% \mathrm{KK}$ & \multicolumn{2}{|c|}{16,31} & \multicolumn{2}{|c|}{11,95} & \multicolumn{2}{|c|}{23,69} & \multicolumn{2}{|c|}{4,47} \\
\hline
\end{tabular}

Keterangan : Angka pada kolom yang sama yang diikuti oleh huruf yang sama, tidak berbeda nyata pada $\alpha$ : $5 \%$; (L1: Lingkungan optimal, L2: Lingkungan genangan)

Jumlah biji pertanaman menunjukkan beda nyata pada lingkungan tanpa genangan (L1) dan lingkungan tergenang (L2). Pada lingkungan genangan jumlah biji yang dihasilkan jauh lebih rendah dibanding tanpa genangan. Dari 3 varietas yang diuji, varietas Demas 1 mempunyai jumlah biji yang paling banyak, kemudian disusul varietas Grobogan dan yang terendah adalah varietas Dega 1 . Jumlah biji pertanaman dan perlakuan lingkungan menunjukkan interaksi yang berbeda nyata.

Karakter bobot biji pertanaman pada perlakuan lingkungan tanpa genangan (L1) dan lingkungan genangan (L2) berbeda nyata. Pada lingkungan genangan bobot biji pertanaman lebih rendah dibanding tanpa genangan. Bobot biji pertanaman varietas Grobogan dan Dega 1 tidak berbeda nyata namun kedua varietas tersebut berbeda nyata dengan Demas 1. Varietas Demas 1 mempunyai jumlah biji lebih banyak apabila dibandingkan dengan varietas Grobogan dan Dega 1, namun mempunyai bobot biji pertanaman lebih rendah dibanding kedua varietas tersebut. Kemungkinan karena ukuran biji varietas Demas 1 yang termasuk kedelai ukuran biji sedang, sedangkan varietas Grobogan dan Dega 1 termasuk kedelai ukuran biji besar. Rata-rata penurunan bobot biji per tanaman apabila dibandingkan antara lingkungan tanpa genangan (L1) dan lingkungan genangan (L2) adalah sebesar $86 \%$ dan varietas Grobogan mengalami penurunan bobot biji per tanaman terendah apabila dibandingkan dengan varietas Demas 1 dan Dega 1. Fatimah dan Sutrisno (2016) melaporkan bahwa varietas Grobogan tercekam genangan pada fase vegetatif mengalami penurunan berat biji hingga $60,41 \%$. Cekaman genangan menyebabkan penurunan jumlah polong dan jumlah biji per polong (Ara et al., 2015)

Pada karakter tinggi tanaman tidak menunjukkan interaksi antara lingkungan tumbuh dengan genotipe kedelai. Peningkatan laju perpanjangan ruas merupakan salah satu mekanisme untuk mengatasi stres akibat cekaman genangan (Mimi, 2015). Namun pada penelitian ini tinggi tanaman pada dua lingkungan tumbuh tidak menunjukkan perbedaan yang.

Pada karakter bobot segar tajuk dan bobot segar akar, terdapat interaksi antara perlakuan lingkungan dan varietas. Berdasarkan data yang diperoleh, varietas Grobogan dan Dega 1 menunjukkan selisih bobot segar tajuk dan bobot segar akar yang lebih sedikit dibandingkan varietas Demas 1 di antara dua lingkungan tumbuh. Genotipe yang toleran terhadap genangan mampu mempertahankan pertumbuhan akar, batang dan daun pada cekaman genangan sehingga tidak kehilangan bobot kering terlalu banyak dibandingkan dengan genotipe yang peka (Ara et al., 2015). 
Tabel 3. Bobot segar tajuk dan akar serta bobot kering tajuk dan akar varietas kedelai pada dua lingkungan

\begin{tabular}{|c|c|c|c|c|c|c|c|c|}
\hline \multirow[t]{2}{*}{ Varietas } & \multicolumn{2}{|c|}{$\begin{array}{l}\text { Bobot segar } \\
\text { tajuk }(\mathrm{g})\end{array}$} & \multicolumn{2}{|c|}{$\begin{array}{l}\text { Bobot segar } \\
\text { akar }(\mathrm{g})\end{array}$} & \multicolumn{2}{|c|}{$\begin{array}{l}\text { Bobot kering } \\
\text { tajuk (g) }\end{array}$} & \multicolumn{2}{|c|}{$\begin{array}{l}\text { Bobot kering akar } \\
(\mathrm{g})\end{array}$} \\
\hline & L1 & L2 & L1 & L2 & L1 & L2 & L1 & L2 \\
\hline Grobogan & $4,52 \mathrm{c}$ & $5,87 \mathrm{c}$ & $2,75 b$ & $4,4 a b$ & $3,45 d$ & $4,7 \mathrm{c}$ & $1,17 \mathrm{c}$ & $3,22 b$ \\
\hline Demas 1 & $45,25 \mathrm{a}$ & $23,8 b$ & $3,65 b$ & $5,97 \mathrm{a}$ & $17,82 \mathrm{a}$ & $6,6 b$ & $1,8 \mathrm{c}$ & $4,05 \mathrm{a}$ \\
\hline Dega 1 & $6,1 c$ & $4,32 \mathrm{c}$ & $1,65 \mathrm{c}$ & $3,9 b$ & $3,67 \mathrm{~cd}$ & $4,27 \mathrm{~cd}$ & $1,12 \mathrm{c}$ & $3,15 b$ \\
\hline Rata-rata & 18,62 & 11,33 & 2,68 & 4,76 & 8,31 & 5,19 & 1,36 & 3,47 \\
\hline$\% \mathrm{KK}$ & 13,51 & & 18,92 & & 10,97 & & 9,22 & \\
\hline
\end{tabular}

Cekaman genangan juga menyebabkan penurunan bobot kering brangkasan. Diantara tiga varietas yang digunakan, varietas Demas 1 mengalami penurunan bobot kering tajuk dan akar paling banyak dibandingkan dengan varietas Grobogan dan Dega 1 apabila dibandingkan dengan kontrol masing-masing varietas. Menurut penelitian Mimi (2015), pada genotipe yang peka cekaman genangan, penurunan bobot kering brangkasan lebih tinggi dibandingkan dengan genotipe yang toleran. Berdasarkan hal tersebut bahwa varietas Grobogan dan Dega 1 lebih toleran pada cekaman genangan dibandingkan varietas Demas 1.
Berdasarkan bobot segar akar dan bobot kering akar dari ketiga varietas yang diuji bahwa pertumbuhan akar pada lingkungan genangan lebih banyak dibandingkan dengan lingkungan tanpa genangan. Kemungkinan hal tersebut adalah mekanisme untuk mengatasi cekaman stres genangan dengan tumbuhnya akar adventif. Tanaman yang beradaptasi dengan kondisi tergenang air, memiliki mekanisme untuk mengatasi stres seperti pembentukan aerenkim dan pembentukan akar adventif (Valliyodan et al., 2014). Aerenkim tidak ditemukan pada akar tanaman yang tidak tergenang air, namun, aerenkim melimpah di akar tanaman yang tergenang air.

Tabel 4. Indeks klorofil varietas kedelai pada dua dua lingkungan

\begin{tabular}{lcccccccc}
\hline Varietas & \multicolumn{2}{c}{$\begin{array}{c}\text { Indeks klorofil } \\
\text { 20 hst }\end{array}$} & \multicolumn{2}{c}{$\begin{array}{c}\text { Indeksi klorofil } \\
\text { 30 hst }\end{array}$} & \multicolumn{2}{c}{$\begin{array}{c}\text { Indeks klorofil } \\
\text { L1 hst }\end{array}$} & \multicolumn{2}{c}{$\begin{array}{c}\text { Indeks klorofil } \\
50 \text { hst }\end{array}$} \\
\cline { 2 - 9 } & L1 & L2 & L1 & L2 & L1 & L2 & L1 & L2 \\
\hline Grobogan & $34,95 \mathrm{a}$ & $33,55 \mathrm{a}$ & $41,67 \mathrm{a}$ & $33,55 \mathrm{c}$ & $43,3 \mathrm{a}$ & $26,85 \mathrm{c}$ & $43,7 \mathrm{a}$ & $27,17 \mathrm{~d}$ \\
Demas 1 & $33,35 \mathrm{a}$ & $30,60 \mathrm{a}$ & $38,87 \mathrm{~b}$ & $32,37 \mathrm{c}$ & $36,32 \mathrm{~b}$ & $25,87 \mathrm{c}$ & $35,97 \mathrm{~b}$ & $29,95 \mathrm{c}$ \\
Dega 1 & $36,95 \mathrm{a}$ & $32,65 \mathrm{a}$ & $40,67 \mathrm{a}$ & $31,5 \mathrm{~cd}$ & $42,47 \mathrm{a}$ & $25,87 \mathrm{c}$ & $42,07 \mathrm{a}$ & $21,4 \mathrm{e}$ \\
\hline Rata-rata & 35.08 & 32,27 & 40,40 & 32,47 & 40,70 & 26,20 & 40,58 & 26,17 \\
\hline \% KK & 7,31 & & 3,16 & & 3,92 & & 3,57 & \\
\hline
\end{tabular}

Keterangan : Angka pada kolom yang sama yang diikuti oleh huruf yang sama, tidak berbeda nyata pada $\alpha$ : $5 \%$; (L1: Lingkungan optimal, L2: Lingkungan genangan)

Semua varietas mengalami penurunan Indeks klorofil daun pada lingkungan genangan dibanding tanpa genangan pada 30 hst, 40 hst maupun 50 hst (Tabel 4). Respon yang diberikan masing-masing varietas terhadap perlakuan genangan berbeda. Pada umur 20 hst, indeks klorofil dari ketiga varietas yang diuji tidak berbeda nyata. Varietas Demas 1 mempunyai indeks klorofil paling rendah pada umur 30 hst, 40 hst dan 50 hst apabila dibandingkan dengan varietas yang lain. Interaksi antara lingkungan dan varietas menunjukkan tidak beda nyata pada karakter indeks klorofil yang diukur pada 20 hst dan 30 hst. Interaksi antara lingkungan dan varietas berpengaruh nyata terhadap indeks klorofil pada umur 40 hst dan 50 hst. Nilai indeks klorofil pada lingkungan genangan mengalami penurunan sedangkan pada lingkungan tanpa genangan relatif stabil. Genangan 
menyebabkan gangguan respirasi sehingga terjadi gangguan penyerapan hara dan akhirnya akan menyebabkan gangguan pembentukan klorofil (Fatimah dan Saputro, 2016). Nilai indeks klorofil menggambarkan level kandungan pigmen untuk proses fotosintesis. Pada kondisi tergenang, tanaman mengalami klorosis dan daun yang menguning dan terjadi reduksi pigmen untuk fotosintesis, reduksi pigmen untuk fotosintesis tersebut akan meningkat seiring dengan lamanya genangan (Mimi, 2015).

\section{PENUTUP}

Perlakuan genangan mengakibatkan penurunan komponen hasil dan hasil kedelai sebanyak $\pm 85 \%$ dibandingkan dengan lingkungan tanpa genangan. Perlakuan genangan meningkatkan bobot kering akar sebanyak $60 \%$ dibandingkan perlakuan tanpa genangan. Varietas Grobogan dan Dega 1 pada lingkungan genangan mempunyai bobot biji pertanaman $\pm 95 \%$ lebih tinggi dibandingkan varietas Demas 1 pada lingkungan genangan.

\section{DAFTAR PUSTAKA}

Ara, R., Mannan, M.A., Khaliq, Q.A., Uddin, M.M., Miah. (2015). Waterlogging Tolerance of Soybean. Bangladesh Agron J. 18 (2):105-109.

Balitkabi. (2016). Deskripsi Varietas Unggul Kacang-kacangan dan Umbi-umbian. Balai penelitian Tanaman Kacangkacangan dan Umbi-umbian. Badan Penelitian dan pengembangan Pertanian. Kementerian Pertanian.

Hapsari, R.T., Adie, M.M. (2010). Pelaung Perakitan dan Pengembangan Kedelai Toleran Genangan. Jurnal Litbang Pertanian 29 (2): 50-57.

Fatimah, V.S., Saputro. T.B. 2016. Respon karakter fisiologis kedelai (Glycine max L.) varietas grobogan terhadap cekaman genangan. Jurnal sains dan seni ITS, Vol. 5 (2): 71-77.
Islam, M.R., Akter, N., Parvej, S.M.S., Haque, K.M.S. (2014). Growth and yield responce of mungbean (Vigna radiata $\mathrm{L}$. Wilczek) genotypes to wet puddling, flooding and saturated soil culture. Journal of Plant Sciences 2 (6): 311-316

Mimi, A. (2015). Legumes: A Study of Waterlogging Tolerance in Gazipur, Bangladesh. Indian Res. J. Ext. Edu 15 (4): 243-257.

Suhartina, Purwantoro, Nugrahaeni, N., Sulistyo, A. 2(016). The adaptability of soybean promising lines to saturated water soil condition. Transaction of Persatuan Genetik Malaysia, No.3: 163168

Tamang, B.G., Fukao, T. (2015). Review: Plant Adaptation to Multiple Stresses during Submergence and Following Desubmergence. International Journal of Molecular Sciences. 16: 30164-30180. doi:10.3390/ijms161226226.

Sumarno, Dauphin, F., Rachim, A., Sunarlim, N., Santoso, B., Kuntyastusi. (1988). Soybean Yield Gap Analysis in Java. CRIFT-ESCAP CGPRT. Bogor. 71 pp

Valliyodan, B., Van Toai, T.T., Alves, J.D., de Fatima, P., Goulart, P., Lee, J.D., Fritschi, F.B., Rahman, M.A., Islam, R., Shannon, J.G., Nguyen, H.T. (2014). Expression of Root-Related Transcription Factors Associated with Flooding Tolerance of Soybean (Glycine max). Int. J.Mol. Sci. 15:17622-17643, doi: 10.3390/ijms151017622. 